\title{
Thymosin $\beta 4$ is associated with bone sialoprotein expression via ERK and Smad3 signaling pathways in MDPC-23 odontoblastic cells
}

\author{
BAIK-DONG CHOI ${ }^{1 *}$, HEE-JUNG LIM ${ }^{2 *}$, SEUNG-YEON LEE ${ }^{1}$, MYOUNG-HWA LEE ${ }^{1}$, \\ KI-SUNG KIL ${ }^{1}$, DO-SEON LIM ${ }^{2}$, SOON-JEONG JEONG ${ }^{3}$ and MOON-JIN JEONG ${ }^{1}$ \\ ${ }^{1}$ Department of Oral Histology and Developmental Biology, College of Dentistry, Chosun University, \\ Gwangju 61452; ${ }^{2}$ Department of Dental Hygiene, College of Health Science, Eulji University, \\ Seongnam, Gyeonggi-do $13135 ;{ }^{3}$ Department of Dental Hygiene, College of Health Science, \\ Youngsan University, Yangsan, Gyeongsangnam-do 50510, Republic of Korea
}

Received April 5, 2018; Accepted August 27, 2018

DOI: $10.3892 / \mathrm{ijmm} .2018 .3865$

\begin{abstract}
Thymosin $\beta 4$ ( $\mathrm{T} \beta 4)$ regulates the expression of molecules associated with dentinogenesis, including bone sialoprotein (BSP). BSP regulates the initiation of mineralization and the direction of dentin growth. However, the association between T $\beta 4$ signaling and BSP expression in odontoblasts remains unclear. Therefore, the aim of the present study was to investigate $\mathrm{T} \beta 4 \mathrm{mRNA}$ expression in odontoblasts during dentinogenesis and the association between the $\mathrm{T} \beta 4$ signaling pathway and BSP expression in MDPC-23 odontoblastic cells. Expression and localization of $\mathrm{T} \beta 4 \mathrm{mRNA}$ was determined by in situ hybridization during mouse tooth development. The effect of T $\beta 4$ signaling on BSP expression was investigated by reverse transcription polymerase chain reaction, western blot analysis, immunofluorescence and a luciferase reporter assay in the presence or absence of specific inhibitors of mitogen activated protein kinase kinase (PD98059) and mothers against decapentaplegic homolog 3 (Smad3; SIS3) in MDPC-23 cells. The expression of T $\beta 4 \mathrm{mRNA}$ in the odontoblast layer was highest at postnatal day 5, known as the advanced bell stage, when odontoblasts actively secrete dentin matrix proteins. T $\beta 4$ increased BSP mRNA and protein levels in MDPC-23 cells, but this was inhibited by PD98059 or SIS3 treatment. $\mathrm{T} \beta 4$ increased levels of phosphorylated (p) extracellular
\end{abstract}

Correspondence to: Professor Moon-Jin Jeong, Department of Oral Histology and Developmental Biology, College of Dentistry, Chosun University, 309 Pilmun-daero, Dong-gu, Gwangju 61452, Republic of Korea

E-mail: mjjeong@chosun.ac.kr

${ }^{*}$ Contributed equally

Key words: thymosin $\beta 4$, bone sialoprotein, extracellular signal-regulated kinase, mothers against decapentaplegic homolog 3, odontoblast, dentin signal-regulated kinase (ERK)1/2, pSmad3, p $\beta$-catenin, and runt-related transcription factor 2 (Runx2) protein, but these effects were inhibited by PD98059 or SIS3. T $\beta 4$ induced the nuclear translocation of Runx 2 and pSmad3, while nuclear translocation of $\beta$-catenin was decreased. $\mathrm{T} \beta 4$ significantly increased BSP promoter activity, which was decreased by PD98059 or SIS3 treatment. T $\beta 4$ induced BSP expression in MDPC-23 cells via ERK and Smad3 signaling pathways, suggesting its role as a signaling molecule in odontoblasts for regulating BSP secretion during dentinogenesis.

\section{Introduction}

Thymosin $\beta 4$ (T $\beta 4)$, a 4.9-kDa small peptide composed of 43 amino acids, was first extracted from the thymus and is the most abundant type of thymosin in mammals (1). T $\beta 4$ participates in regulating cell proliferation, differentiation and motility (2). Our previous study demonstrated that T $\beta 4$ expression increases MC3T3-E1 cell viability on titanium (Ti) discs by increasing adhesion and proliferation (3). T $\beta 4$ is expressed and involved in the initiation, formation and differentiation of tooth germ during molar development $(4,5)$. T $\beta 4$-overexpressing transgenic mice exhibit abnormal tooth development resembling enamel hyperplasia (6). T $\beta 4$ knockdown with small interfering RNA (siRNA) significantly decreases mRNA levels of noncollagenous proteins and type I collagen (COL type I) during MDPC-23 odontoblastic cell differentiation (7).

Dentinogenesis is regulated in odontoblasts by a complex signaling cascade that promotes the expression of dentin matrix-associated proteins (8). Dentin is composed of the mineral hydroxyapatite and organic materials including collagen and noncollagenous proteins. Among noncollagenous proteins, bone sialoprotein (BSP) is one of the major proteins in mineralized tissues including bone, dentin, cementum and calcified cartilage (9). BSP is a phosphorylated or sulfurized glycoprotein with high levels of a sialic acid, for example osteopontin, and tends to bind with hydroxyapatite $(10,11)$. BSP serves as the nucleator of primary apatite crystals, and 
it regulates the direction of ribbon-like apatite crystal growth on collagen during mineralization (12). Protamine increases BSP expression via mitogen-activated protein kinase (MAPK) signaling in osteoblasts (13). Transforming growth factor $\beta 1$ (TGF- $\beta 1$ ) inhibits BSP expression and osteoblast formation from human mesenchymal stem cells via mothers against decapentaplegic homolog $3(\mathrm{Smad} 3) / \beta$-catenin signaling (14). $\mathrm{T} \beta 4$ increases MC3T3-E1 cell viability by activating the paired box (Pax)/focal adhesion kinase (FAK) and FAK/growth factor receptor-bound protein 2 (Grb2)/Ras/extracellular signal-regulated kinase (ERK) signaling pathways and promoting focal adhesion and proliferation on Ti discs (3). In addition, $\mathrm{T} \beta 4$ increases gastric cancer cell migration by downregulating E-cadherin through the ERK/glycogen synthase kinase $3 \alpha / \beta$-catenin signaling pathway (15).

The authors' previous study identified that $\mathrm{T} \beta 4$ protein expression was highest in the secretory odontoblast layer during the advanced bell stage of dentinogenesis (7). It was also identified that $\mathrm{T} \beta 4$ promotes differentiation and mineralization of the osteoblastic MC3T3-E1 cell line on Ti discs (16). These previous studies indicated that $\mathrm{T} \beta 4$ serves as a principle molecule during the formation of mineralized tissues including bone and dentin. However, T $\beta 4$-associated signaling is not fully understood in odontoblasts, and specifically, the association between T $\beta 4$ signaling and BSP has not been elucidated. Therefore, we hypothesized and investigated whether $\mathrm{T} \beta 4$ signaling may regulate BSP expression in odontoblasts. To the best of our knowledge, the present study identified for the first time that T $\beta 4$ upregulates BSP by activating ERK and Smad3 signaling in MDPC-23 odontoblastic cells, suggesting its role as a principle regulatory signaling molecule in dentin matrix formation during dentinogenesis.

\section{Materials and methods}

Tissue preparation. A total of 3 pregnant adult ICR outbred female mice, 10-weeks old, weighing 50-60 g (Samtako Bio Korea Osan, Gyeonggi-do, Korea), were used. The temperature and humidity was maintained at $23 \pm 2{ }^{\circ} \mathrm{C}$ and $60 \pm 10 \%$, respectively. The animals were kept in a $12 \mathrm{~h}$ light-dark photoperiod and provided with pelleted mouse chow and tap water ad libitum. The animal protocols were approved by the Institutional Animal Care and Use Committees at Chosun University (Gwangju, Korea), and animal care was performed using specific-pathogen-free systems according to the Guide for the Care and Use of Laboratory Animals (17). The heads of mice at postnatal day 1 (PN1), PN3, PN5, PN15, and PN21 were used in the present study. The heads, dissected from PN1, PN3, and PN5 mice, were fixed in 4\% paraformaldehyde (PFA) in diethylpyrocarbonate-treated phosphate-buffer saline (DEPC-PBS, pH 7.4) at $4^{\circ} \mathrm{C}$ for $24 \mathrm{~h}$. The PN15 and PN21 mice were fixed by the intracardiac perfusion of $4 \%$ PFA. The heads of the PN15 and PN21 mice were dissected and fixed an additional $18 \mathrm{~h}$ in fresh $4 \% \mathrm{PFA}$ at $4^{\circ} \mathrm{C}$. Tissues were decalcified in a solution of $10 \%$ ethylenediaminetetraacetic acid (EDTA) supplemented with $1 \%$ PFA at $27-28^{\circ} \mathrm{C}$ for 4 weeks. After decalcification, the heads were dehydrated by sequential washes in 70, 80, 90, $100 \mathrm{I}, 100 \mathrm{II}$ and $100 \%$ III at $27-28^{\circ} \mathrm{C}$ for $1 \mathrm{~h}$ and finally in $100 \% \mathrm{IV}$ ethanol for $18 \mathrm{~h}$. Paraffin-embedded tissues were cut into $6-\mu \mathrm{m}$ thick sections using a Histocut 820 (Leica Microsystems, Wetzlar, Germany) and were subsequently placed onto glass slides and dried on a $37^{\circ} \mathrm{C}$ slide warmer overnight.

Synthesis of T $\beta 4$ complementary RNA (cRNA) probes and peptides. Gene-specific probes for the 405-bp T $\beta 4$ cDNA were designed according to methods described previously (5). The pGEM-3Z vector (Promega Corporation, Madison, WI, USA) containing a T $\beta 4$ cDNA insert was linearized by digestion with restriction enzymes (EcoRI or HindIII) to synthesize T $\beta 4$ sense (S) and antisense (AS) cRNA probes using an in vitro transcription kit (Roche Applied Science, Penzberg, Germany). The probes were labeled with digoxigenin (DIG)-11-UTP using a SP6/T7 DIG RNA Labeling kit (Roche Diagnostics, Basel, Switzerland). The full amino acid sequence of the mouse T $\beta 4$ peptide, Ac-SDKPDMAEIEKFDKSKLKKTETQEKNP LPSKETIEQEKQAGES, was synthesized by solution phase peptide synthesis (A\&PEP, Cheongju-si, Chungcheongbuk-do, Korea).

Membrane hybridization. Unlabeled S probes were anchored to the nucleic acid transfer membranes (GE Healthcare Life Sciences, Little Chalfont, UK) using a ultraviolet crosslinker (Stratagene; Agilent Technologies, Inc., Santa Clara, CA, USA). The membrane-anchored unlabeled $S$ probes were incubated with DIG-labeled AS probes mixed with unlabeled S or unlabeled AS (1-10 ng/ $\mu \mathrm{l})$ in the hybridization solution. The DIG-labeled AS probes were reacted with alkaline phosphatase (AP)-conjugated DIG antibodies and then detected using a DIG nucleic acid detection kit (Roche Diagnostics).

In situ hybridization. Tissue sections were deparaffinized sequentially in xylene I and II at $27-28^{\circ} \mathrm{C}$ for $5 \mathrm{~min}$. For rehydration, the sections were incubated sequentially in $100,90,80$ and $70 \%$ ethanol at $27-28^{\circ} \mathrm{C}$ for $1 \mathrm{~min}$. Following deparaffinization and hydration, the tissue sections were incubated with proteinase $\mathrm{K}$ at $37^{\circ} \mathrm{C}$ for $12 \mathrm{~min}$ and then $4 \% \mathrm{PFA}$ at $27-28^{\circ} \mathrm{C}$ for $10 \mathrm{~min}$. Subsequently, sections were immersed in $0.1 \mathrm{M}$ triethanolamine- $\mathrm{HCl}$ (TEA-HCl) and $0.25 \%$ acetic anhydride (in 0.1 M TEA) to remove background signals. Hybridization was performed with the hybridization mixture (hybridization solution, $1 \mathrm{ng} / \mu \mathrm{l}$ DIG-labeled S or DIG-labeled AS). The sections were washed twice in $2 \mathrm{X}$ and $0.2 \mathrm{X}$ saline-sodium citrate buffer containing $50 \%$ formamide, and then incubated with a 1:500 dilution of AP-conjugated DIG antibodies at $27-28^{\circ} \mathrm{C}$ for $1 \mathrm{~h}$. This DIG-labeled S or DIG-labeled AS probes analysis was performed using a DIG nucleic acid detection kit (cat. no. 11175041 910; Roche Diagnostics), and sections were counterstained with $1 \%$ methyl green $(10 \mathrm{mg} / \mathrm{ml}$, Vector Laboratories, Inc., Burlingame, CA, USA) at $27-28^{\circ} \mathrm{C}$ for $20 \mathrm{sec}$. The stained tissue was observed by optical microscopy (Carl Zeiss AG, Oberkochen, Germany) on bright field for T $\beta 4$ mRNA detection. The expression of T $\beta 4$ mRNA in the tissue was analyzed using a bright field microscope and Axiovision LE 4.6 software (Carl Zeiss AG).

Cell culture. MDPC-23 cells (provided by Dr CT Hanks from University of Michigan, Ann Arbor, MI, USA), an odontoblastic cell line derived from the dental papilla of fetal mouse molars, were cultured in Dulbecco's modified Eagle medium 
(Gibco; Thermo Fisher Scientific, Inc., Waltham, MA, USA) supplemented with $10 \%$ fetal bovine serum (Welgene, Inc., Gyeongsan-si, Korea) and $1 \%$ antibiotic-antimycotic solution (Welgene, Inc.). Cells were incubated in a humidified chamber maintained with $5 \% \mathrm{CO}_{2}$ at $37^{\circ} \mathrm{C}$.

Extraction of total $R N A$ and reverse transcription $(R T)$ semi-quantitative polymerase chain reaction $(P C R)$. Following serum starvation in serum free medium, MDPC-23 cells were treated with $2 \mu \mathrm{g} / \mathrm{ml} \mathrm{T} \beta 4$ (T $\beta 4 / \mathrm{MDPC}-23$ ) for $24 \mathrm{~h}$ (18). Total RNA was extracted from the cells using TRIzol ${ }^{\circledR}$ reagent (Molecular Research Center, Inc., Cincinnati, OH, USA) according to the manufacturer's protocol, and PCR was performed using AmpONE Taq premix (GeneAll Biotechnology, Co., Ltd., Seoul, Korea). The following primers were synthesized by Bioneer, Co., Ltd. (Daejeon, Korea) for RT-PCR analysis: BSP forward, 5'-ACCGGC CACGCTACTTTCTTTAT-3'; BSP reverse, 5'-TCCTCGTCG CTT TCCTTCACT TT-3'; GAPDH forward, 5'-CCATGG AGAAGGCTGGG-3'; GAPDH reverse,5'-CAAAGTTGTCAT GGATGACC-3'. Each PCR reaction consisted of an initial denaturation at $95^{\circ} \mathrm{C}$ for 2 min followed by three-step cycling: Denaturation at $95^{\circ} \mathrm{C}$ for $20 \mathrm{sec}$, annealing at a temperature optimized for each primer pair for $10 \mathrm{sec}\left(\mathrm{BSP}, 60^{\circ} \mathrm{C}\right.$ for 30 cycles; GAPDH, $56^{\circ} \mathrm{C}$ for 30 cycles), and extension at $72^{\circ} \mathrm{C}$ for $30 \mathrm{sec}$. Single bands were observed at the expected sizes of 358 bp for BSP (GenBank \#L20232) and 199 bp for GAPDH (GenBank \#M33197) by agarose gel electrophoresis. The PCR products were electrophoresed on $1.5 \%$ agarose gel buffered with $0.5 \mathrm{X}$ Tris-Borate-EDTA (TBE) buffer and stained with ethidium bromide after amplification. The bands were visualized using a Gel-Doc system (BioRad Laboratories, Inc., Hercules, CA, USA). Band intensities were measured to determine differences in mRNA expression using Science Lab Image Gauge software version 3.12 (Fujifilm Corporation, Tokyo, Japan).

Protein extraction and western blot analysis. Following serum starvation in serum free medium, MDPC-23 cells were treated with $2 \mu \mathrm{g} / \mathrm{ml} \mathrm{T} \beta 4$ (T $\beta 4 / \mathrm{MDPC}-23)$ at $37^{\circ} \mathrm{C}$ for 6,12 or $24 \mathrm{~h}$. TGF- $\beta 1$ (10 ng/ml; R\&D Systems, Inc., Minneapolis, $\mathrm{MN}, \mathrm{USA}$ ) was also added to a group of MDPC-23 cells (TGF- $\beta 1 / \mathrm{MDPC}-23$ ) at $37^{\circ} \mathrm{C}$ for $30 \mathrm{~min}$. Certain MDPC-23 cells were treated with the mitogen activated protein kinase kinase inhibitor PD98059 (Sigma-Aldrich; Merck KGaA, Darmstadt, Germany) or the Smad3 phosphorylation inhibitor SIS3 (Sigma-Aldrich; Merck KGaA) at $5 \mu \mathrm{M}$ (PD98059/MDPC-23 and SIS3/MDPC-23, respectively) at $37^{\circ} \mathrm{C}$ for $1 \mathrm{~h}$ to examine the effects of these inhibitors alone. In addition, MDPC-23 cells were pretreated with PD98059 and SIS3 for $1 \mathrm{~h}$ prior to T $\beta 4$ treatment (T/34/PD98059/MDPC-23 and $\mathrm{T} \beta 4 / \mathrm{SIS} / \mathrm{MDPC}-23$, respectively). Subsequent to the various treatments, proteins were extracted from the cells using NP-40 lysis buffer [150 mM NaCl, 1\% NP-40, $50 \mathrm{mM}$ Tris- $\mathrm{HCl}$ ( $\mathrm{pH}$ 7.4), $2 \mathrm{mM} \mathrm{Na} \mathrm{VO}_{4}, 2 \mathrm{mM} \mathrm{Na}_{4} \mathrm{P}_{2} \mathrm{O}, 50 \mathrm{mM} \mathrm{NaF}$, $2 \mathrm{mM}$ EDTA (pH 7.4), $0.1 \mu \mathrm{g} / \mathrm{ml}$ of leupeptin and $1 \mu \mathrm{g} / \mathrm{ml}$ of aprotinin], and the proteins (30 $\mu \mathrm{g}$ per lane) were electrophoresed on $7.5 \%$ SDS-PAGE gels. Following electrophoresis, proteins were transferred to PVDF membranes and blocked with either $5 \%$ non-fat dry milk or $5 \%$ bovine serum albumin
(BioShop Canada, Inc., Burlington, ON, Canada) at $27-28^{\circ} \mathrm{C}$ for $1 \mathrm{~h}$ in TBS with $0.05 \%$ Tween-20 (TBS-T) buffer. The membranes were blotted with specific antibodies at $4^{\circ} \mathrm{C}$ for $16 \mathrm{~h}$ against phosphorylated (p) $\beta$-catenin (cat. no. 4176; $1: 1,000), \beta$-catenin (cat. no. $8480 ; 1: 1,000)$, pERK1/2 (cat. no. 9106; 1:2,500), ERK1/2 (cat. no. 9102; 1:2,500), pSmad2 (cat. no. 3108; 1:1,000), pSmad3 (cat. no. 9502; 1:1,000), or Smad2/3 (cat. no. 3102; 1:1,000) from Cell Signaling Technology , Inc., (Danvers, MA, USA); BSP (cat. no. AB1854; 1:2,500) from Merck KGaA; and runt-related transcription factor 2 (Runx2, cat. no. sc-10758; dilution, $1: 2,000$ ) or $\beta$-actin (cat. no. sc-47778; 1:2,500) from Santa Cruz Biotechnology, Inc. (Dallas, TX, USA). Membranes were then blotted with horseradish peroxidase-conjugated goat anti-rabbit (cat. no. sc-2004; 1:10,000) or mouse-IgG antibodies (cat. no. sc-2005; 1:10,000) at $27-28^{\circ} \mathrm{C}$ for $1 \mathrm{~h}$ as appropriate (Santa Cruz Biotechnology, Inc.). Immunoreactive bands were detected using X-ray film (Fujifilm Corporation) following treatment with enhanced chemiluminescent solution (Merck KGaA). The intensity of expressed bands was measured by densitometry using Science Lab Image Gauge software version 3.12 (Fujifilm Corporation).

Immunofluorescence. MDPC-23 cells were serum starved in serum free medium and then treated with $2 \mu \mathrm{g} / \mathrm{ml} \mathrm{T} \beta 4$ and $5 \mu \mathrm{M}$ PD 98059 or SIS3 for $24 \mathrm{~h}$. Cells were fixed in $4 \%$ formaldehyde at $27-28^{\circ} \mathrm{C}$ for $15 \mathrm{~min}$, treated with $0.1 \mathrm{M}$ glycine, then permeabilized with $0.2 \%$ Triton $\mathrm{X}-100$ for $5 \mathrm{~min}$, and blocked with $5 \%$ normal goat serum (Vector Laboratories, Inc.) at $27-28^{\circ} \mathrm{C}$ for $1 \mathrm{~h}$. Cells were incubated with a $1: 100$ dilution of anti-rabbit BSP, pSmad3, $\beta$-catenin, or Runx2 antibodies at $4^{\circ} \mathrm{C}$ overnight. A 1:1,000 dilution of fluorescein isothiocyanate-conjugated goat-anti-rabbit IgG (Santa Cruz Biotechnology, Inc.; cat. no. sc-2012) was used as a secondary antibody. Cells were mounted with DAPI (Vector Laboratories, Inc.) for nuclear staining and images were captured at $\mathrm{x} 400$, magnification using a fluorescence microscope (Carl Zeiss AG). The fluorescence intensity of $\beta$-catenin, Runx 2 and pSmad3 protein in the nucleus compared with the cytoplasm was measured by ImageJ 1.8.0 software (National Institutes of Health, Bethesda, MD, USA). At least 100 cells were counted in 3 different microscopic fields. The measurement and quantification methods were performed as described previously (19).

Plasmid construction and transfection. The $2.5 \mathrm{~kb}$ portion of the mouse BSP gene promoter region from $-2,472$ to +41 was artificially synthesized (Bioneer, Co., Ltd.; https://www. bioneer.co.kr) and cloned into the Nhe I-Xho I site of the pGL3-basic vector (pGL3-BSP-Luc). The pGL3-basic vector was supplied from Promega Corporation (Madison, WI, USA). All construct identities were verified by DNA sequencing and restriction enzyme digestion. MDPC-23 cells were transfected with $2 \mu \mathrm{g} / \mathrm{ml}$ pGL3-basic vector (pGL3-Luc; $\left.3.85 \times 10^{11} / \mathrm{ml}\right)$ or $2 \mu \mathrm{g} / \mathrm{ml}$ pGL3-BSP-Luc $\left(2.53 \times 10^{11} / \mathrm{ml}\right)$ for $48 \mathrm{~h}$ using WellFect-EX (Welgene, Inc.) according to the manufacturer's protocol and transfected cells were used subsequent experiment after serum starvation for $16 \mathrm{~h}$.

Luciferase assay. The pGL3-BSP-Luc-transfected MDPC-23 cells were treated with $2 \mu \mathrm{g} / \mathrm{ml} \mathrm{T} \beta 4$ (pGL3-BSP-Luc/T $\beta 4$ ), 
or $5 \mu \mathrm{M}$ PD98059 or SIS3 (pGL3-BSP-Luc/PD98059 or pGL3-BSP-Luc/SIS3, respectively), for $24 \mathrm{~h}$ after serum starvation in serum free medium. In addition, the pGL3-BSP-Luc/T $\beta 4$ cells were pretreated with PD98059 or SIS3 at $37^{\circ} \mathrm{C}$ for $1 \mathrm{~h}$ prior to T $\beta 4$ treatment (pGL3-BSP-Luc/PD98059 or SIS3/T/34) for $24 \mathrm{~h}$. Protein extraction and reaction with luciferase substrates were performed using a luciferase assay kit (Promega Corporation; cat. no. E1500) according to the manufacturer's protocol. Luciferase activity as proxy for BSP expression was measured using a luminometer (Thermo Fisher Scientific, Inc.). The luciferase activity of pGL3-basic vector was used for normalization.

Statistical analysis. All experiments were performed at least in triplicate. Values are expressed as the mean \pm standard error of the mean. Statistical analysis was performed using SPSS v25 (IBM Corp., Armonk, NY, USA). Differences between samples among multiple groups were compared by one-way analysis of variance (ANOVA). The Tukey's post hoc method was used to perform pairwise comparisons following ANOVA. $\mathrm{P}<0.01$ was considered to indicate a statistically significant difference.

\section{Results}

$T \beta 4 m R N A$ is expressed in odontoblasts during postnatal dentinogenesis. To determine DIG-labeled AS binding activity, the hybridization signal between the mixture of DIG-labeled AS and unlabeled S was determined, and membrane-fixed unlabeled $\mathrm{S}$ was detected upon the addition of $1 \mathrm{ng} / \mu 1$ of unlabeled $\mathrm{S}$ mixture, but was not detected upon the addition of 5 or $10 \mathrm{ng} / \mu \mathrm{l}$. In addition, the hybridization signal between the mixture of DIG-labeled AS and unlabeled AS, and membrane-fixed unlabeled $\mathrm{S}$ was most marked upon addition of the $1 \mathrm{ng} / \mu \mathrm{l}$ unlabeled AS mixture, and was gradually decreased upon addition of the 5 and $10 \mathrm{ng} / \mu 1$ solutions (Fig. 1A). T $\beta 4$ mRNA was increased in odontoblasts at the advanced bell stage (PN5), and was observed in the odontoblasts of the crown (PN15) and functional stages (PN21) with a pattern similar to that observed in the early bell stage (PN1). Dentin deposition was observed at PN1 during the early bell stage and became thickened with the increase in enamel at PN3 and PN5 during the advanced bell stage (Fig. 1B and C).

$T \beta 4$ increases BSP expression by activating ERK/Runx 2 or $E R K / \beta$-catenin signaling in MDPC-23 cells. In MDPC-23 cells treated with T $\beta 4$ for $24 \mathrm{~h}$, the levels of BSP mRNA and protein were increased compared with the levels observed in untreated control cells (Fig. 2A). Furthermore, immunofluorescence analysis indicated that $\mathrm{T} \beta 4$ treatment increased BSP protein levels compared to the levels observed in untreated control cells (Fig. 2B). To identify the effect of T $\beta 4$ on pERK1/2,p $\beta$-catenin and $\beta$-catenin expression, MDPC-23 cells were treated with $\mathrm{T} \beta 4$ at different time intervals $(5,10,15$ and $30 \mathrm{~min})$. The levels of pERK1/2 and $\mathrm{p} \beta$-catenin increased the most, but $\beta$-catenin was decreased at $10 \mathrm{~min}$ in MDPC-23/T $\beta 4$ cells compared with that of the control (data not shown). pERK1/2 and $\mathrm{p} \beta$-catenin levels were decreased in the PD98059/MDPC-23 and T/44/PD98059/MDPC-23 groups compared with those in the T $\beta 4 /$ MDPC-23 cells. $\beta$-catenin levels were increased in the PD98059/MDPC-23 group compared with levels in the T $\beta 4 /$ MDPC-23 cells. Expression levels of Runx2 and BSP were increased in the T $\beta 4 /$ MDPC-23 cells compared with that in the untreated control cells, but levels of the 2 proteins were decreased in the PD98059/MDPC-23 and T/34/PD98059/MDPC-23 groups compared with that in the T $\beta 4 / M D P C-23$ cells (Fig. 2C). Upon T $\beta 4$ treatment for 6-24 h, levels of $p \beta$-catenin were increased but levels of cytosolic and nuclear $\beta$-catenin protein were decreased in the T $\beta 4 /$ MDPC-23 cells compared with levels in the control cells. Cytosolic and nuclear levels of Runx 2 protein were increased in the T $\beta 4 / M D P C-23$ cells after $6 \mathrm{~h}$ of treatment compared with that of the control cells. BSP expression increased time-dependently in the T/44/MDPC-23 cells compared with that in the control cells (Fig. 2D). Furthermore, levels of nuclear $\beta$-catenin were increased in the T/34/PD98059/MDPC-23 cells compared with levels in the T $\beta 4 /$ MDPC-23 cells, and PD98059 inhibited the T $\beta 4$-induced nuclear localization of Runx2 (Fig. 2E and F).

TR4 increases BSP expression by activating Smad3/Runx2 or Smad3/ $\beta$-catenin signaling in MDPC-23 cells. pSmad2 levels were significantly increased in the TGF- $\beta 1 /$ MDPC- 23 cells treated for 30 min compared with levels in the control, but pSmad 2 was not induced in the T $\beta 4 /$ MDPC- 23 cells. pSmad3 levels were increased in the TGF- $\beta 1 /$ MDPC-23 and T $\beta 4 / M D P C-23$ cells compared with levels in the control cells (Fig. 3A). Smad2 phosphorylation was not induced in the T $\beta 4$ /MDPC-23 cells, but pSmad3 was significantly increased in the T $\beta 4 /$ MDPC-23 cells treated for 5 to 30 min compared with that in the control (Fig. 3B). In the T $\beta 4 /$ MDPC-23 cells, the levels of $\mathrm{pSmad} 3$ and $\mathrm{p} \beta$-catenin were increased compared with the control cells; however, this phosphorylation was decreased in the SIS3/MDPC-23 and T $\beta 4 /$ SIS3/MDPC-23 groups. $\beta$-catenin levels were decreased in the T $\beta 4 /$ MDPC-23 cells compared with that in the control, but $\beta$-catenin levels were similar to the control levels in the SIS3/MDPC-23 and T/34/SIS3/MDPC-23 groups. The expression levels of Runx2 and BSP were increased in the T $\beta 4 /$ MDPC- 23 cells compared with expression in the control, but decreased levels were observed in the SIS3/MDPC-23 and T $\beta 4 /$ SIS3/MDPC-23 groups compared with levels observed in the T $\beta 4 /$ MDPC-23 cells (Fig. 3C). The levels of cytoplasmic and nuclear pSmad3 were increased from 6-24 $\mathrm{h}$ in the T $\beta 4 / \mathrm{MDPC}-23$ cells compared with that in the control. The expression of BSP was increased in the T $\beta 4 /$ MDPC-23 cells compared with the expression in the control cells (Fig. 3D). Furthermore, nuclear pSmad 3 levels were decreased in the T $\beta 4 /$ SIS3/MDPC-23 cells compared with that in the T $\beta 4 /$ MDPC-23 cells, and the nuclear levels of $\beta$-catenin were increased in the T $\beta 4 / \mathrm{SIS} 3 / \mathrm{MDPC}-23$ group (Fig. 3E and F).

TR4 increases BSP promoter activity via ERK and Smad3 signaling. Luciferase activity was significantly increased in the pGL3-BSP-Luc cells compared with that in the pGL3-Luc cells, and it was also increased in the pGL3-BSP-Luc/T $\beta 4$ group compared with that in the pGL3-BSP-Luc group $(\mathrm{P}<0.01)$. Compared with the pGL-BSP-Luc/T $\beta 4$ cells, the luciferase activity was significantly decreased upon treatment with PD98059 or SIS3. Furthermore, luciferase activity was decreased in the pGL-BSP-Luc/SIS3/T $\beta 4$ cells compared with 
A
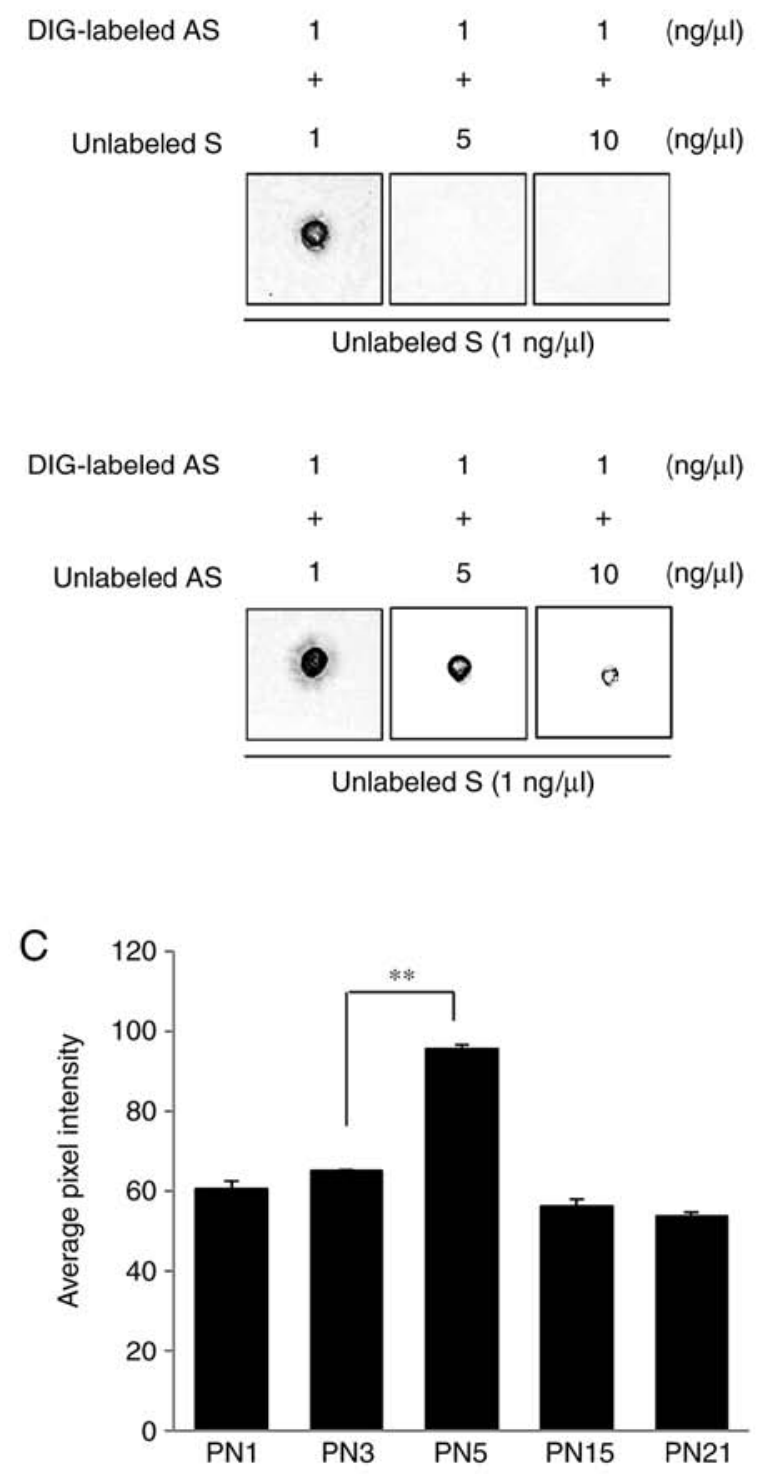

B

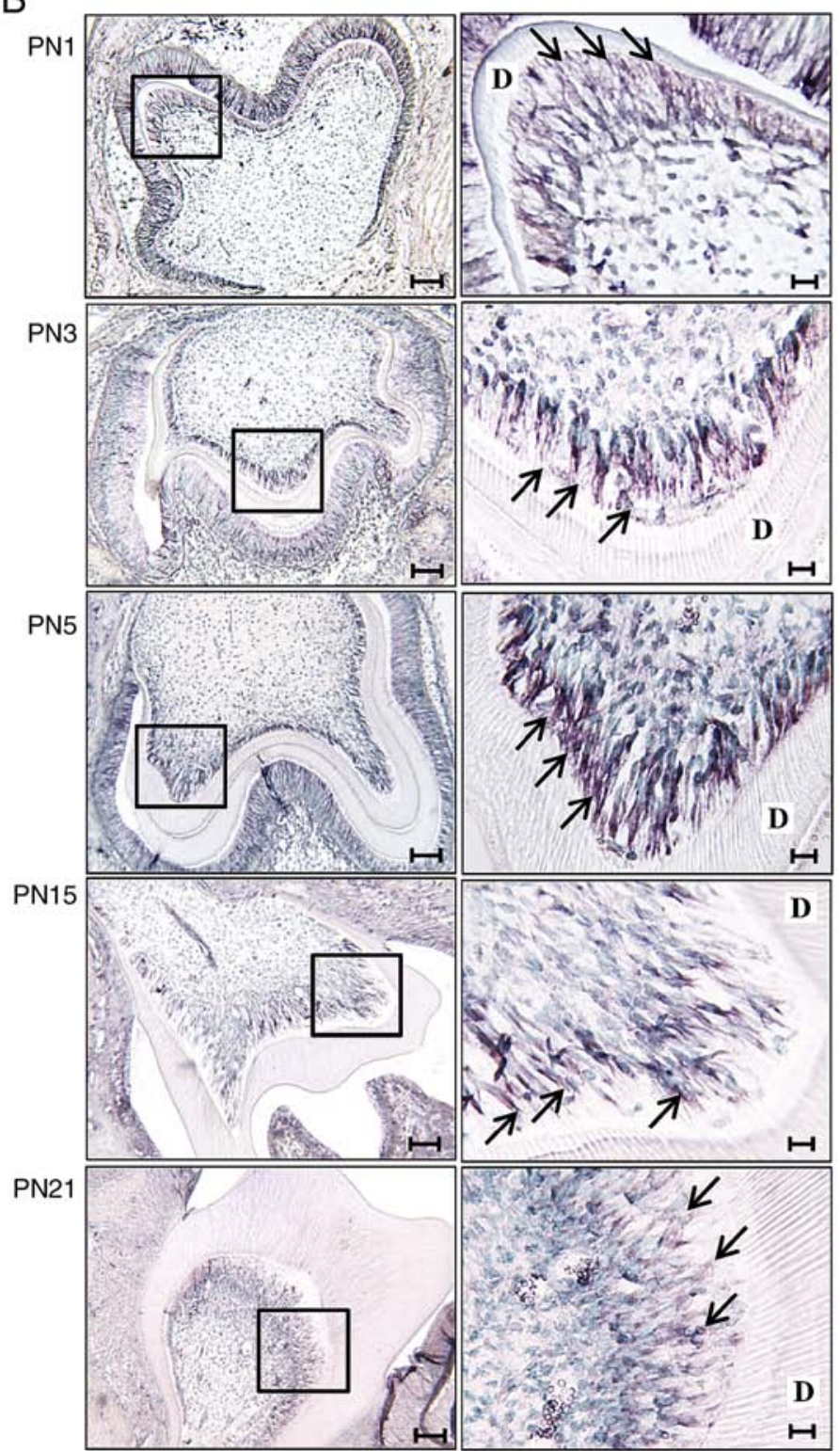

Figure 1. Specificity and binding activity analysis of in situ probes through membrane hybridization and T $\beta 4$ mRNA expression in odontoblasts during dentinogenesis. (A) The hybridization signal between DIG-labeled AS probes (1 ng/ml) and membrane-dotted unlabeled S probes (1 ng/ml) was decreased by increasing the concentration of unlabeled S (upper panel) or unlabeled AS (lower panel) in the mixture. (B) Low (left, magnification, x100) and high (right, magnification, $\mathrm{x} 400)$ magnification images of mouse molar tooth germ from PN1 to PN21. The right-hand column shows the area within the black box magnified to $\mathrm{x} 400$. Expression of T $\beta 4$ mRNA was increased in odontoblasts (arrows) at the advanced bell stage (PN5), and the expression at the crown (PN15) and functional (PN21) stages were similar to expression observed at the early bell stage (PN1). Scale bars=100 $\mu \mathrm{m}$ (left) and $20 \mu \mathrm{m}$ (right). (C) The hybridization signal intensity of T $\beta 4$ mRNA was most marked in the PN5 odontoblasts. ${ }^{*} \mathrm{P}<0.01$. T $\beta 4$, thymosin $\beta 4$; PN1, postnatal day 1 ; PN3, postnatal day 3; PN5, postnatal day 5; PN15, postnatal day 15; PN21, postnatal day 21; D, dentin; AS, antisense; S, sense; DIG, digoxigenin.

in the pGL-BSP-Luc/PD98059/T $\beta 4$ cells (Fig. 4A). Fig. 4B is a schematic diagram of the experimental results demonstrating that $\mathrm{T} \beta 4$ induced BSP expression via ERK or Smad3 signaling associated with Runx 2 and $\beta$-catenin in MDPC-23 cells.

\section{Discussion}

Odontoblast differentiation occurs actively at the early bell stage, and secretory odontoblasts are present in the cusp and cervical region of developing molars at advanced bell stages $(7,20,21)$. Secretory odontoblasts secrete non-collagenous proteins including BSP, dentin sialoprotein, osteocalcin (OCN) and osteonectin at the advanced bell stage (22-24). Our previous study indicated that $\mathrm{T} \beta 4$ protein levels are increased in odontoblasts at the cusp and cervical region of developing molars in the advanced bell stage, compared with levels in early bell stages (7). Other studies suggested that $\mathrm{T} \beta 4$ is associated with enamel development and tooth germ growth $(6,25)$. In the present study, T $\beta 4$ mRNA was markedly expressed in odontoblasts at the cusp region in the advanced bell stage concordantly with the activation of dentin matrix synthesis during dentinogenesis. Therefore, in accordance with previous studies, the marked expression of T $\beta 4$ mRNA in secretory odontoblasts indicated that T $\beta 4$ may regulate odontoblast differentiation or dentin formation 

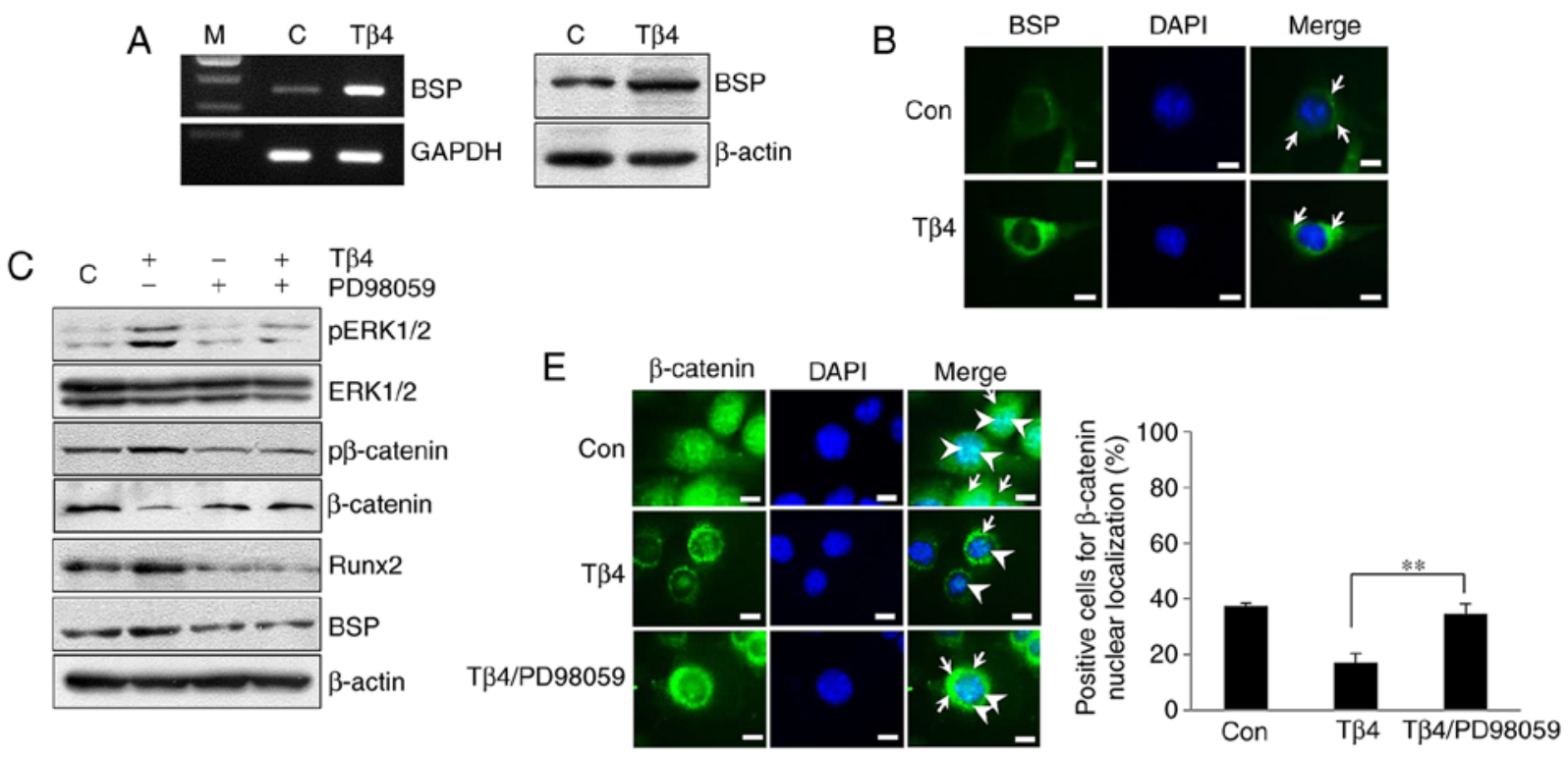

D

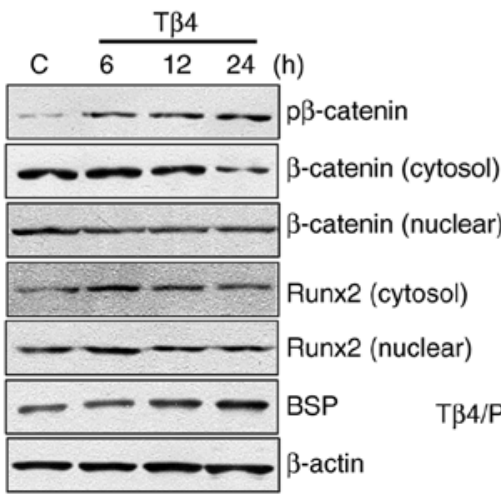

$\mathrm{F}$
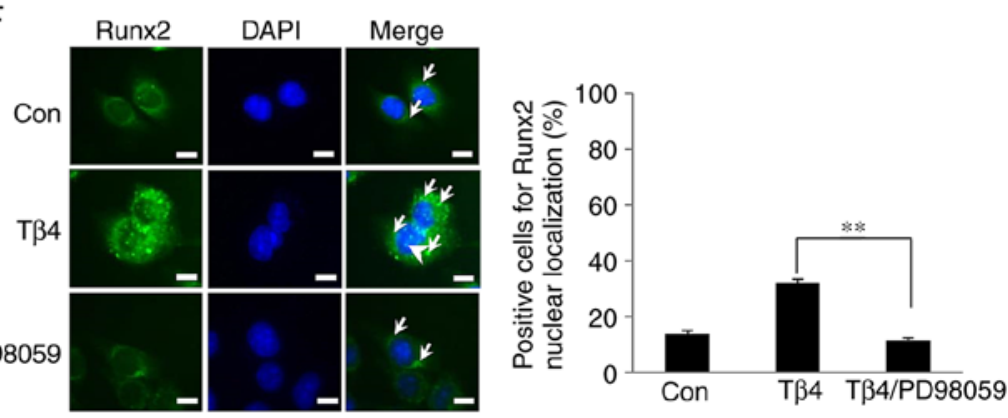

Figure 2. BSP expression through ERK/Runx2 and ERK/ $\beta$-catenin signaling in T $\beta 4$-treated MDPC-23 cells. (A) BSP mRNA (left panel) and protein (right panel) levels were increased in the MDPC-23 cells treated with T $\beta 4$ compared with levels in the untreated control cells. (B) Immunofluorescence analysis indicated increased BSP protein (arrows) in the cytoplasm following T $\beta 4$ treatment. (C) Levels of pERK1/2 and p $\beta$-catenin decreased, while Runx2 and BSP protein decreased in the PD98059/MDPC-23 and T 34 /PD98059/MDPC-23 groups compared with the T $\beta 4 /$ MDPC-23 group. (D) Cytoplasmic and nuclear $\beta$-catenin levels were decreased in the T $\beta 4 /$ MDPC-23 cells compared with levels in the untreated control cells. Cytoplasmic and nuclear Runx2 protein levels were increased following $6 \mathrm{~h}$ of $\mathrm{T} \beta 4$ treatment compared with the untreated control cells. (E) Immunofluorescence images indicating cytoplasmic (arrows) and nuclear (arrowheads) $\beta$-catenin levels upon T $\beta 4$ treatment. (F) Runx2 protein levels in the cytoplasm (arrows) and nucleus (arrowheads) were increased in T $\beta 4 / \mathrm{MDPC}-23$ cells compared with levels in the untreated control cells, but were decreased in the PD98059/MDPC-23 cells compared with levels in the T $\beta 4 /$ MDPC- 23 cells. Scale bars $=20 \mu \mathrm{m}$. The histograms indicate the percentage of cells positive for $\beta$-catenin and Runx 2 in the MDPC- 23 group. ${ }^{* *} \mathrm{P}<0.01$. ERK, extracellular signal-regulated kinase; Runx2, runt-related transcription factor 2; p, phosphorylated; T $\beta 4$, Thymosin $\beta 4$; BSP, bone sialoprotein; Con, control.

during tooth development. Our previous study demonstrated that $\mathrm{T} \beta 4$ knockdown remarkably decreases mineralization and mRNA expression of non-collagenous proteins including BSP during MDPC-23 cell differentiation (7). In bone tissue, which is similar to dentin, transgenic BSP knockout mice form undermineralized bones, and their cortical bones are thinner compared with the cortical bones of normal mice (26). These studies suggest that T $\beta 4$ may regulate BSP expression during mineralized tissue development. In the present study, T $\beta 4$ treatment increased BSP mRNA and protein levels in MDPC-23 cells compared with levels in untreated control cells. This suggests that $\mathrm{T} \beta 4$ may regulate BSP expression in odontoblasts through intracellular signal transduction during dentinogenesis.

In a pulldown experiment to identify differential interacting proteins, $\mathrm{T} \beta 4$ was demonstrated to increase extracellular adenosine 5'-triphosphate (ATP) levels via ecto-ATP synthase on the cell surface (27). Increased ATP was demonstrated to activate $\mathrm{P} 2 \mathrm{X}$ purinoreceptor 4 purinergic receptors to promote the migration of endothelial cells. In a recent study, purinergic receptor subtypes, including P2X4, were expressed in dental pulp cells (DPCs) and ATP was revealed to promote the odontoblastic differentiation and mineralization of DPCs (28). Our previous studies demonstrated autocrine and paracrine actions of $T \beta 4$, similar to results of other studies $(27,29)$. Suppression of $T \beta 4$ expression significantly decreases the mRNA expression of mineralization-associated factors, including BSP, and mineralization in MDPC-23 cells (7). In addition, exogenous $\mathrm{T} \beta 4$ increases osteoblast-like cell adhesion on Ti surfaces, but the suppression of T $\beta 4$ expression significantly inhibits this adhesion (3). Exogenous T $\beta 4$ has also been indicated to stimulate angiogenesis through increased endothelial cell differentiation and migration, thereby allowing $\mathrm{T} \beta 4$ to function in autocrine and paracrine manners (29). Therefore, based 
A

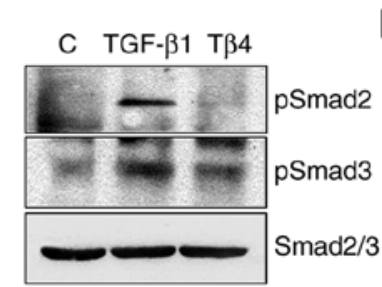

B

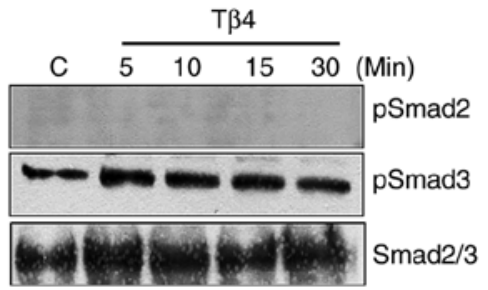

C

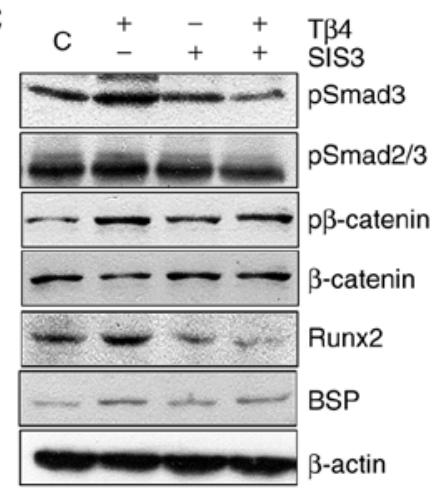

D
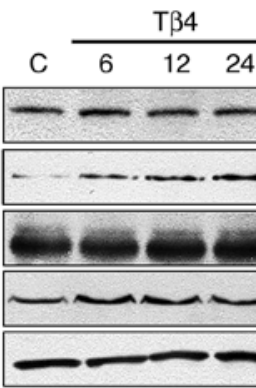

\section{(h)}

pSmad3 (cytosol)

pSmad3 (nuclear)

Smad2/3

BSP

$\beta$-actin
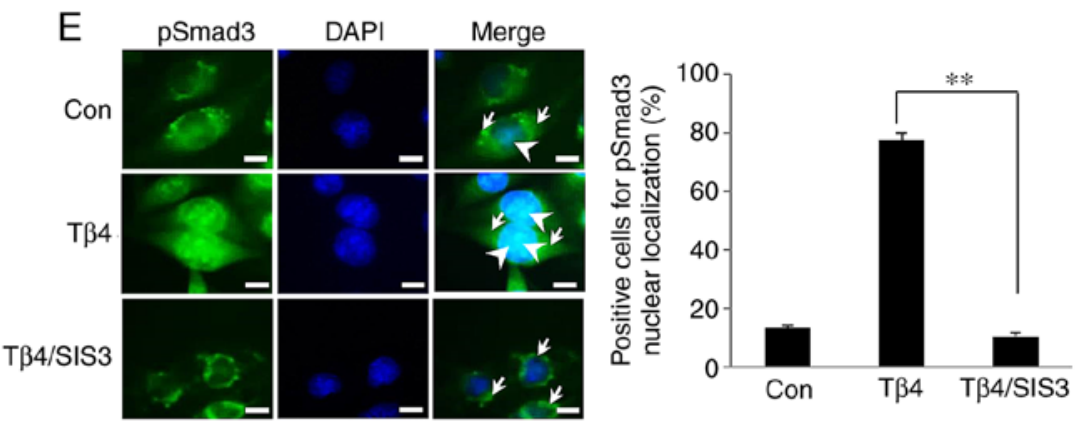

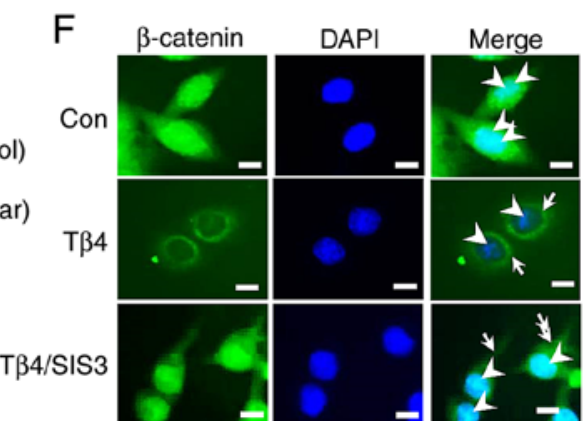

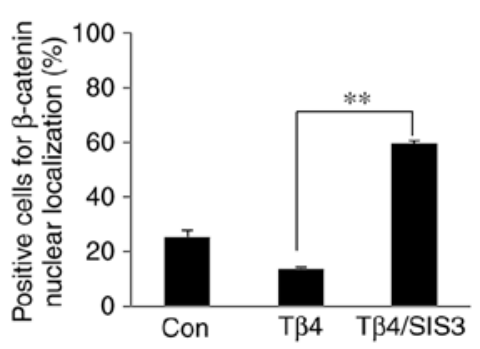

Figure 3. BSP expression through Smad3, Smad3/Runx2 and Smad3/ $\beta$-catenin signaling in T $\beta 4$-treated MDPC-23 cells. (A) Levels of pSmad3, but not $\mathrm{pSmad} 2$, were increased in the T $\beta 4 / \mathrm{MDPC}-23$ cells compared with levels in the untreated control cells. (B) Smad3 phosphorylation was increased by T $\beta 4$ treatment at all time points in MDPC-23 cells. (C) Levels of pSmad3 and $\mathrm{p} \beta$-catenin were decreased in SIS3/MDPC-23 and T $34 / \mathrm{SIS} 3 / \mathrm{MDPC}-23$ cells compared with levels in the T $\beta 4 /$ MDPC-23 cells. (D) Levels of cytosolic and nuclear pSmad 3 were increased in the T $\beta 4 / M D P C-23$ cells compared with levels in the untreated control cells. (E) Immunofluorescence images indicating pSmad3 in the cytoplasm (arrows) and nucleus (arrowheads). (F) Levels of $\beta$-catenin in the cytoplasm (arrows) and nucleus (arrowheads) were decreased upon T $\beta 4$ treatment but were increased in the SIS3/MDPC-23 cells compared with that in the T $\beta 4 / M D P C-23$ cells. Scale bars $=20 \mu \mathrm{m}$. The histograms indicate the percentage of cells positive for $\mathrm{pSmad} 3$ and $\beta$-catenin in the MDPC-23 group. ${ }^{* *} \mathrm{P}<0.01$. T $\beta 4$, Thymosin $\beta 4$; BSP, bone sialoprotein; Con, control. Smad3, mothers against decapentaplegic homolog 3; Smad2, mothers against decapentaplegic homolog 2; p, phosphorylated; Runx2, runt-related transcription factor 2.

on these data from our studies and additional previous studies, $\mathrm{T} \beta 4$ may regulate BSP expression by autocrine or/and paracrine signaling and additional studies are required for determining the receptor of $\mathrm{T} \beta 4$ in odontoblasts during dentinogenesis.

$\mathrm{T} \beta 4$ is an actin-sequestering peptide that regulates actin polymerization, and T $\beta 4$ may also activate signaling pathways involved with cell migration, adhesion and proliferation, including ERK/ $\beta$-catenin, Pax/FAK and FAK/Grb2/Ras/ERK in osteoblasts and gastric cancer cells $(3,15)$. T $\beta 4$ is expressed in developing mouse mandibles and is also involved in the initiation, formation and differentiation of tooth germ during molar development $(4,5)$. In a previous study, $\mathrm{T} \beta 4$ promoted the odontoblastic differentiation of dental pulp cells by activating MAPKs [p38 MAPK, c-Jun N-terminal kinase (JNK) and ERK], and Smad (Smad1/5/8 and Smad2/3) signaling pathways (30). ERK, p38 and JNK have critical functions in signal transduction during embryo development, immune response and neural canal development in vertebrates $(31,32)$. In addition, MAPKs are the central signal transducers that modulate osteogenesis and bone mass $(33,34)$. ERK1/2 signaling activates Runx2 and therefore OCN expression during osteoblast differentiation (35). In the present study, it was identified that $\mathrm{T} \beta 4$ increases pERK1/2 levels and Runx2 expression in MDPC-23 cells. Additionally, T $\beta 4$ increased Runx2 nuclear translocation in MDPC-23 cells. In previous studies, Wnt3a stimulation increased the nuclear translocation of $\beta$-catenin, thereby decreasing the expression of Runx2, osterix, alkaline phosphatase (ALP), BSP, and OCN in cementoblasts and dental follicle cells $(36,37)$. In the present study, $T \beta 4$ reduced cytoplasmic and nuclear $\beta$-catenin levels in MDPC-23 cells. Considering all these results together, $\mathrm{T} \beta 4$ signal transduction increases BSP expression through ERK/Runx 2 or ERK/ $\beta$-catenin in MDPC-23 cells.

Smad proteins are additional important signal transducers associated with tooth development. BMP-2 increases Runx2 expression through the Smad1/5 pathway, which also increases the expression of ALP and OCN through the $\beta$-catenin pathway in dental papilla cells $(38,39)$. TGF- $\beta 1$ inhibits the differentiation of mesenchymal stem cells into osteoblasts by elevating $\beta$-catenin levels via Smad3, protein kinase A (PKA) 

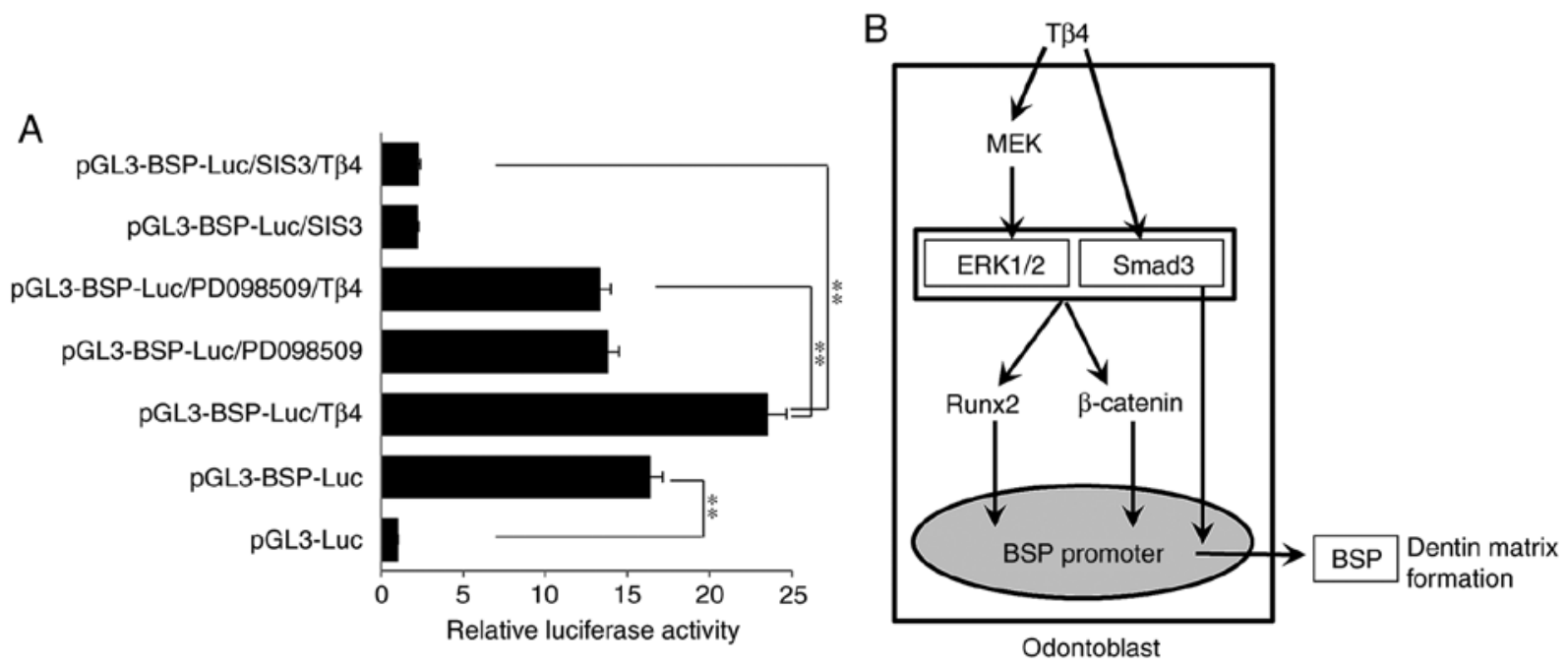

Figure 4. BSP promoter activity through ERK1/2 and Smad3 signaling in T $\beta 4$-treated MDPC-23 cells and schematic diagram of the association between T $\beta 4$-mediated signaling and BSP expression. (A) Luciferase activity in pGL-BSP-Luc/T $\beta 4$ cells compared with that in pGL-BSP-Luc cells. The activity of the pGL-BSP-Luc/PD98059 or pGL-BSP-Luc/PD98059/T 34 cells was decreased compared with that of the pGL-BSP-Luc/T 34 cells. In the pGL-BSP-Luc/SIS3 and pGL-BSP-Luc/SIS3/T $\beta 4$ groups, luciferase activity was decreased compared with that of the pGL-BSP-Luc/T $\beta 4$ group. ${ }^{* *} \mathrm{P}<0.01$. (B) T $\beta 4-\mathrm{mediated}$ ERK or Smad3 signaling was transduced to downstream signaling molecules including Runx 2 and $\beta$-catenin, which induces BSP expression, resulting in dentin matrix formation in odontoblasts. T $\beta 4$, Thymosin $\beta 4$; BSP, bone sialoprotein; MEK, mitogen activated protein kinase kinase; ERK, extracellular signal-regulated kinase; Smad3, mothers against decapentaplegic homolog 3; Runx2, runt-related transcription factor 2.

and phosphoinositide 3-kinase (PI3K) signaling, thereby decreasing BSP expression (14). Cytosolic Smad2 or Smad3 translocate into the nucleus by interacting with Smad4, where they regulate the expression of genes associated with bone matrix synthesis including Runx2, ALP, COL type I and OCN in MC3T3-E1 cells $(40,41)$. In a recent study, T $\beta 4$ knockdown decreased Runx2 expression via Smad1/5/8 and PI3K/protein kinase B (Akt) signaling in dental epithelial cells (42). The results of the present study indicated that $T \beta 4$ increased Smad3 phosphorylation and expression of Runx2, but did not increase the phosphorylation of Smad2 in MDPC-23 cells. In addition, $\mathrm{T} \beta 4$ increased nuclear pSmad3 levels in MDPC-23 cells. T $\beta 4$ also decreased cytoplasmic and nuclear $\beta$-catenin through Smad3 signaling, similarly to pERK1/2 signaling, in MDPC-23 cells. Therefore, the present results indicated that T $\beta 4$ increased BSP expression through Smad3/Runx2, Smad3/ $\beta$-catenin and Smad3 signal transduction in MDPC-23 cells.

According to the results of the present study, T $\beta 4$ induced BSP expression via ERK and Smad3 signaling in MDPC-23 cells. However, it is necessary to determine which pathway is more important for T $\beta 4$-mediated BSP expression in MDPC-23 cells. A previous study suggested that protamine-induced BSP promoter activation was significantly more suppressed by ERK1/2 inhibitor treatment (U0126) compared with protein kinase C or PKA inhibitor treatment (H7 or KT5720) in ROS 17/2.8 osteoblast-like cells (13). SIS3 treatment inhibits TGF- $\beta 1$-induced $\beta$-catenin transcription and stabilization in mesenchymal stem cells, but these phenomena are not affected by PD98059 treatment (14). Additionally, T $\beta 4$ increases Runx2 expression via Smad1/5/8 and PI3K/Akt signaling to a lesser degree compared with ERK/MAPK signaling in dental epithelial cells (42). In the present study, T $\beta 4$ increased BSP promoter activity, which was decreased by PD98059 or SIS3 treatment in MDPC-23 cells. Notably, BSP promoter activity was significantly more inhibited by SIS3 treatment compared with PD98059 treatment. These results indicated that T $\beta 4$ activated BSP transcription via ERK and Smad3 signaling, and that Smad3 signaling contributed to T $\beta 4$-induced BSP transcription in MDPC-23 cells to a greater extent compared with ERK signaling.

In conclusion, T $\beta 4$ induced BSP in MDPC-23 cells through ERK and Smad3 pathways, suggesting its role as a signaling molecule for regulating BSP secretion in odontoblasts. These events indicate that $\mathrm{T} \beta 4$ signaling may be associated with dentin matrix formation in odontoblasts during dentinogenesis. Additional examination of the receptor of $\mathrm{T} \beta 4$ in odontoblasts during dentinogenesis is required.

\section{Acknowledgements}

Not applicable.

\section{Funding}

The present study was supported by the National Research Foundation of Korea funded by the Ministry of Science, ICT \& Future Planning (grant no. R13-2008-010-01001-0).

\section{Availability of data and materials}

All data generated or analyzed during this study are included in this published article.

\section{Authors' contributions}

BDC, HJL and MJJ contributed to the design of the study and performed the experiments. BDC, SYL, MHL, and KSK analyzed the experimental data. BDC and MJJ drafted the manuscript. DSL and SJJ were involved in revising manuscript 
critically for important intellectual content. All the authors read and approved the final manuscript.

\section{Ethics approval and consent to participate}

Animal studies were approved by the Institutional Animal Care and Use Committees of Chosun University (Gwangju, Korea).

\section{Patient consent for publication}

Not applicable.

\section{Competing interests}

The authors declare that they have no competing interests.

\section{References}

1. Low TL, Hu SK and Goldstein AL: Complete amino acid sequence of bovine thymosin beta 4: A thymic hormone that induces terminal deoxynucleotidyl transferase activity in thymocyte populations. Proc Natl Acad Sci USA 78: 1162-1166, 1981.

2. Goldstein AL, Hannappel E and Kleinman HK: Thymosin beta4 Actin-sequestering protein moonlights to repair injured tissues Trends Mol Med 11: 421-429, 2005.

3. Choi BD, Jeong SJ, Lee HY, Lim DS, Lee BH, Bae CS and Jeong MJ: The effect of thymosin $\beta 4$ for osteoblast adhesion on titanium surface. J Nanosci Nanotechnol 15: 5663-5667, 2015.

4. Yamaza H, Matsuo K, Kiyoshima T, Shigemura N, Kobayashi I, Wada H, Akamime A and Sakai H: Detection of differentially expressed genes in the early developmental stage of the mouse mandible. Int J Dev Biol 45: 675-680, 2001

5. Akhter M, Kobayashi I, Kiyoshima T, Matsuo K, Yamaza H, Wada H, Honda JY and Sakai H: Possible functional involvement of thymosin beta 4 in developing tooth germ of mouse lower first molar. Histochem Cell Biol 124: 207-213, 2005.

6. Cha HJ, Philp D, Lee SH, Moon HS, Kleinman HK and Nakamura T: Over-expression of thymosin beta 4 promotes abnormal tooth development and stimulation of hair growth. Int J Dev Biol 54: 135-140, 2010.

7. Choi BD, Yun SH, Jeong SJ, Wang G, Kim HJ, Lim DS and Jeong MJ: Expression of thymosin $\beta 4$ in odontoblasts during mouse tooth development. Int J Mol Med 29: 841-847, 2012.

8. Matalová E, Lungová V and Sharpe P: Development of tooth and associated structure. In: Stem cell biology and tissue engineering in dental science. ScienceDirect (ed). Elsevier Inc., San Diego, pp335-346, 2015.

9. Macneil RL, Sheng N, Strayhorn C, Fisher LW and Somerman MJ: Bone sialoprotein is localized to the root surface during cementogenesis. J Bone Miner Res 9: 1597-1606, 1994.

10. Oldberg A, Franzén A and Heinegård D: The primary structure of a cell-binding bone sialoprotein. J Biol Chem 263: 19430-19432, 1988.

11. Stubbs JT III, Mintz KP, Eanes ED, Torchia DA and Fisher LW: Characterization of native and recombinant bone sialoprotein: Delineation of the mineral-binding and cell adhesion domains and structural analysis of the RGD domain. J Bone Miner Res 12: 1210-1222, 1997

12. Hunter GK and Goldberg HA: Modulation of crystal formation by bone phosphoproteins: Role of glutamic acid-rich sequences in the nucleation of hydroxyapatite by bone sialoprotein. Biochem J 302: 175-179, 1994.

13. Zhou L, Matsumura H, Mezawa M, Takai H, Nakayama Y, Mitarai M and Ogata Y: Protamine stimulates bone sialoprotein gene expression. Gene 516: 228-237, 2013.

14. Zhou SH: TGF- $\beta$ regulates $\beta$-catenin signaling and osteoblast differentiation in human mesenchymal stem cells. J Cell Biochem 112: 1651-1660, 2011.

15. Ryu YK, Lee YS, Lee GH, Song KS, Kim YS and Moon EY: Regulation of glycogen synthase kinase-3 by thymosin beta- 4 is associated with gastric cancer cell migration. Int J Cancer 131: 2067-2077, 2012 .
16. Jeong SJ and Jeong MJ: Effect of thymosin beta4 on the differentiation and mineralization of MC3T3-E1 cell on a titanium surface. J Nanosci Nanotechnol 16: 1979-1983, 2016.

17. No authors listed: Environment, housing, and management. In: Guide for the Care and Use of Laboratory Animals, 8th edition. National Research Council of the National Academies (ed). National Academies Press, Washington, DC, pp41-88, 2011.

18. Oh JM, Ryoo IJ, Yang Y, Kim HS, Yang KH and Moon EY: Hypoxia-inducible transcription factor (HIF)-1 alpha stabilization by actin-sequestering protein, thymosin beta- 4 (TB4) in Hela cervical tumor cells. Cancer Lett 264: 29-35, 2008.

19. Jiang XH, Xie YT, Cai YP, Ren J and Ma T: Effects of hepatitis $\mathrm{C}$ virus core protein and nonstructural protein $4 \mathrm{~B}$ on the Wnt/ $\beta$-catenin pathway. BMC Microbiol 17: 124, 2017.

20. Lisi S, Peterkova R, Peterka M, Vonesch JL, Ruch JV and Lesot H: Tooth morphogenesis and pattern of odontoblast differentiation. Connect Tissue Res 44 (Suppl 1): S167-S170, 2003.

21. Zhang J, Zhang ZG, Morris D, Li Y, Roberts C, Elias SB and Chopp M: Neurological functional recovery after thymosin beta4 treatment in mice with experimental auto encephalomyelitis. Neuroscience 164: 1887-1893, 2009.

22. Fujisawa R and Kuboki Y: Changes in levels of osteonectin in bovine dentine during tooth development. Arch Oral Biol 34: 89-92, 1989.

23. D'Souza RN, Bronckers AL, Happonen RP, Doga DA, Farach-Carson MC and Butler WT: Developmental expression of a $53 \mathrm{KD}$ dentin sialoprotein in rat tooth organs. J Histochem Cytochem 40: 359-366, 1992

24. Bronckers AL, Engelse MA, Cavender A, Gaikwad J and D'Souza RN: Cell-specific patterns of Cbfal mRNA and protein expression in postnatal murine dental tissues. Mech Dev 101: 255-258, 2001 .

25. Ookuma YF, Kiyoshima T, Kobayashi I, Nagata K, Wada H, Fujiwara H, Yamaza H, Nonaka K and Sakai H: Multiple functional involvement of thymosin beta-4 in tooth germ development. Histochem Cell Biol 139: 355-370, 2013.

26. Malaval L, Wade-Gueye NM, Boudiffa M, Fei J, Zirngibl R, Chen F, Laroche N, Roux JP, Burt-Pichat B, Duboeuf F, et al: Bone sialoprotein plays a functional role in bone formation and osteoclastogenesis. J Exp Med 205: 1145-1153, 2008.

27. Freeman KW, Bowman BR and Zetter BR: Regenerative protein thymosin beta-4 is a novel regulator of purinergic signaling. FASEB J 25: 907-915, 2011.

28. Wang W, Yi X, Ren Y and Xie Q: Effects of adenosine triphosphate on proliferation and odontoblastic differentiation of human dental pulp cells. J Endod 42: 1483-1489, 2016.

29. Grant DS, Rose W, Yaen C, Goldstein A, Martinez J and Kleinman H: Thymosin beta4 enhances endothelial cell differentiation and angiogenesis. Angiogenesis 3: 125-135, 1999.

30. Lee SI, Kim DS, Lee HJ, Cha HJ and Kim EC: The role of thymosin beta 4 on odontogenic differentiation in human dental pulp cells. PLoS One 8: e61960, 2013

31. Kuan CY, Yang DD, Samanta Roy DR, Davis RJ, Rakic P and Flavell RA: The Jnk1 and Jnk2 protein kinases are required for regional specific apoptosis during early brain development. Neuron 22: 667-676, 1999.

32. Dong C, Davis RJ and Flavell RA: MAP kinases in the immune response. Annu Rev Immunol 20: 55-72, 2002.

33. Ge C, Xiao G, Jiang D and Franceschi RT: Critical role of the extracellular signal-regulated kinase-MAPK pathway in osteoblast differentiation and skeletal development. J Cell Biol 176: 709-718, 2007.

34. Greenblatt MB, Shim JH, Zou W, Sitara D, Schweitzer M, Hu D, Lotinun S, Sano Y, Baron R, Park JM, et al: The p38 MAPK pathway is essential for skeletogenesis and bone homeostasis in mice. J Clin Invest 120: 2457-2473, 2010.

35. Xiao G, Gopalakrishnan R, Jiang D, Reith E, Benson MD and Franceschi RT: Bone morphogenetic proteins, extracellular matrix, and mitogen-activated protein kinase signaling pathways are required for osteoblast-specific gene expression and differentiation in MC3T3-E1 cells. J Bone Miner Res 17: 101-110, 2002.

36. Nemoto E, Koshikawa Y, Kanaya S, Tsuchiya M, Tamura M, Somerman MJ and Shimauchi H: Wnt signaling inhibits cementoblast differentiation and promotes proliferation. Bone 44: 805-812, 2009.

37. Silvério KG, Davidson KC, James RG, Adams AM, Foster BL, Nociti FH Jr, Somerman MJ and Moon RT: Wnt/ $\beta$-catenin pathway regulates bone morphogenetic protein (BMP2)-mediated differentiation of dental follicle cells. J Periodontal Res 47: 309-319, 2012 
38. Cho YD, Yoon WJ, Woo KM, Baek JH, Park JC and Ryoo HM: The canonical BMP signaling pathway plays a crucial part in stimulation of dentin sialophosphoprotein expression by BMP-2. J Biol Chem 285: 36369-36376, 2010.

39. Koizumi Y, Kawashima N, Yamamoto M, Takimoto K, Zhou M, Suzuki N, Saito M, Harada H and Suda H: Wnt11 expression in rat dental pulp and promotional effects of Wnt signaling on odontoblast differentiation. Congenit Anom (Kyoto) 53: 101-108, 2013.

40. Massagué J and Wotton D: Transcriptional control by the TGF-beta/Smad signaling system. EMBO J 19: 1745-1754, 2000
41. Kaji H, Naito J, Sowa H, Sugimoto T and Chihara K: Smad3 differently affects osteoblast differentiation depending upon its differentiation stage. Horm Metab Res 38: 740-745, 2006.

42. Someya H, Fujiwara H, Nagata K, Wada H, Hasegawa K, Mikami Y, Jinno A, Sakai H, Koyano K and Kiyoshimai T: Thymosin beta 4 is associated with RUNX2 expression through the Smad and Akt signaling pathways in mouse dental epithelial cells. Int J Mol Med 35: 1169-1178, 2015. 